\title{
MORPHOLOGICAL STUDY OF ACHILLES TENDON
}

\section{Pallavi Bajpayee ${ }^{1}$, Shilpa Gosavi *2, P Vatsalaswamy ${ }^{3}$.}

${ }^{1}$ Assistant Professor, Department of Anatomy, Dr. D. Y. Patil Medical College, Dr. D Y Patil Vidyapeeth, Pimpri, Pune, India.

${ }^{* 2}$ Professor, Department of Anatomy, Bharati Vidyapeeth (Deemed to be university)Medical College, Pune, India.

${ }^{3}$ Professor, Department of Anatomy and Director Academics, Dr. D. Y. Patil Medical College, Dr. D Y Patil Vidyapeeth, Pimpri, Pune, India.

\section{ABSTRACT}

Background: The calcaneal tendon is the thickest and strongest tendon in the human body which is attached to the midpoint of the posterior surface of calcaneum. It is a frequent site of rupture, degenerative changes and inflammation.

Aim: To study the anatomical and morphological details of attachment of Achilles tendon.

Materials and Methods: The study was carried out on 70 adult cadaveric lower limbs in two Medical colleges. Various linear measurements were taken with the help of digital vernier caliper, accurate up to $0.01 \mathrm{~mm}$.

Results: Presence of Achilles tendon in all cadaveric limbs was observed in the present study. Bursa between the tendon at insertion and calcaneus was seen in all specimens. Length of tendon of gastrocnemius was observed to vary between $16.5 \mathrm{~cm}$ to $29.5 \mathrm{~cm}$. The width at musculotendinous junction with gastrocnemius was observed to vary between $3.42 \mathrm{~cm}$ to $6.84 \mathrm{~cm}$. Other measurements taken were minimum width, thickness at insertion, length of gastrocnemius aponeurosis medially and laterally.

Conclusion: In the present study, variations in the morphology of Gastrocnemius were observed. Understanding these variations of the gastrocnemius tendon and aponeurosis will aid the surgeon in performing surgical procedures such as pedicle tendon flap for reconstructive surgery and arthroplasty, Endoscopic Gastrocnemius Recession (EGR), on the Achilles tendon and prevent iatrogenic complications. It is also useful to the Anatomists as it will help them integrate in their teaching the variations and thus better prepare the students for their clinical tenures/work/future.

KEY WORDS: Tendoachilles, Repair Of Ruptured Tendon, Reconstructive Surgery, Arthroplasty.

Address for Correspondence: Dr. Shilpa Gosavi, Professor, Department of Anatomy, Bharati Vidyapeeth (Deemed to be university) Medical College, Pune, India.Mob. - 9822218073,

E-Mail: sngosavi@yahoo.com

Access this Article online Quick Response code

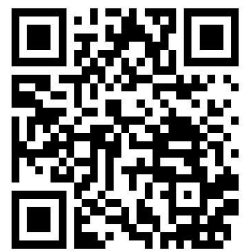

DOI: $10.16965 /$ ijar.2018.448

\begin{tabular}{|c|c|c|}
\hline \multicolumn{3}{|c|}{ Journal Information } \\
\hline \multicolumn{3}{|c|}{$\begin{array}{l}\text { International Journal of Anatomy and Research } \\
\text { or } 2016 \text { ISSN (E) 2321-4287 | ISSN (P) 2321-8967 } \\
\text { 0.30 https://www.ijmhr.org/ijar.htm } \\
\text { DoI-Prefix: https://dx.doi.org/10.16965/ijar }\end{array}$} \\
\hline \multicolumn{3}{|c|}{ Article Information } \\
\hline $\begin{array}{l}\text { Received: } 21 \text { Dec } 2018 \\
\text { Peer Review: } 21 \text { Dec } 2018 \\
\text { Revised: None }\end{array}$ & $\begin{array}{l}\text { Accepted: } 20 \text { Jan } \\
\text { Published }(0): 05 \\
\text { Published }(P): 05\end{array}$ & $\begin{array}{l}9 \\
2019 \\
2019\end{array}$ \\
\hline
\end{tabular}

\section{INTRODUCTION}

Gastrocnemius is the most superficial muscle of the flexor group and forms the belly of the calf. It arises by two heads connected to the condyles of the femur by strong and long tendons. The fleshy part of the muscle extends up to mid-calf. The muscle fibres of the larger medial head extend lower than those of the lateral head. As the muscle descends the muscle fibres begin to insert into a broad aponeurosis 
that develops on its anterior surface; up to this point the muscular masses of the two heads remain separate. The aponeurosis gradually narrows and receives the tendon of soleus on its deep surface to form the calcaneal tendon [1]. The tendoachilles is considered to be the thickest and strongest tendon in the body, being the tendon by which calf muscles exert their force on the posterior part of the foot during the propulsive phase of many activities for example walking, running and jumping[2].

The tendon is wider at its lower end becoming thick and narrower as it descends until it becomes essentially round in cut section superior to calcaneum and its narrowest part is $4 \mathrm{~cm}$ above the insertion. It is inserted in the centre of the posterior surface of calcaneal tuberosity [3]. The variation of the insertion of Achilles tendon can contribute significantly to the mechanical stability and movements of the joints $[4,5]$.

The calf muscle plantar flexes the foot at the ankle joint. Gastrocnemius acts as propelling force, working mainly on the ankle but also producing flexion of the knee joint. Soleus acts more as a postural muscle. This is because its lower attachment is a fixed point and prevents the leg from falling forwards under the influence of body weight, because the vertical projection from the centre of gravity of the body fall in front of ankle joint[2].

The large size of these two muscles is a human feature related to upright posture and bipedalism. These muscles help in lifting, propelling and accelerating the weight of the body when walking, running, jumping or standing on the toes[3].

As compared to humans and gibbons who have a long Achilles tendon, it is short or absent in apes. It provides elastic energy storage in hopping, walking and running[3].

A complete tear of the gastrocnemius tendon is a disabling condition. An acute tear typically occurs in sedentary middle aged men engaged in episodic over activity resulting in forceful dorsiflexion of the foot[6].It may also be chronic.

Present study was carried out with an aim to study the anatomical and morphological details, of the gastrocnemius aponeurosis and that of the tendoachilles.

\section{MATERIALS AND METHODS}

The study was carried out on seventy adult cadaveric lower limbs from Departments of Anatomy of two Medical colleges. The cadavers were in the age group of 50-80 yrs. Various linear measurements were taken with the help of digital vernier caliper accurate up to $0.01 \mathrm{~mm}$. We measured the length of the tendon of gastrocnemius and that of soleus. The width of the achilles tendon was measured at three levels, at its junction with gastrocnemius, at its junction with Soleus and at the level of its insertion. The minimum width of the tendon was measured and the distance of this from the insertion was noted. The thickness of the tendon was noted at its insertion. We also measured the length of aponeurosis of gastrocnemius, length of medial and lateral borders of the aponeurosis of gastrocnemius. The results were tabulated and statistically studied for mean and standard deviation using the SPSS, version 22 software.

Fig.1: Showing the method of taking various measurements.

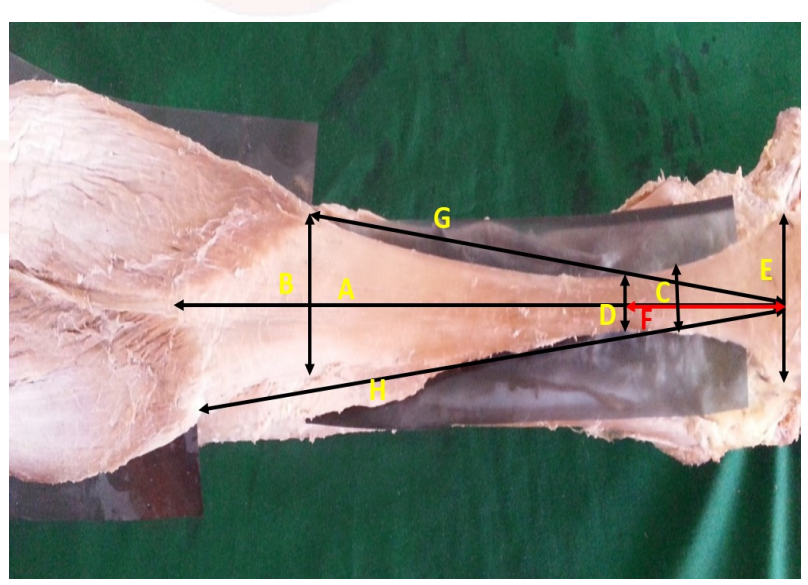

(a) Length of tendon of gastrocnemius ,

(b) Width at the musculotendinous junction with gastrocnemius

(c) Width at $4 \mathrm{cms}$ from insertion

(d) Minimum width of tendon

(e) Width of tendon at insertion

(f) Distance of minimum width from insertion

(g) Length of gastrocnemius aponeurosis at medial border

(h) Length of gastrocnemius aponeurosis at lateral border 


\begin{tabular}{|c|c|c|c|c|}
\hline \multirow{11}{*}{$\begin{array}{c}\text { Table 1: } \\
\text { Morphometrical } \\
\text { parameters of } \\
\text { Achillis tendon. }\end{array}$} & & MEASUREMENTS TAKEN & RANGE (cm) & MEAN +SD $(\mathrm{cm})$ \\
\hline & 1 & Length of tendon at junction with gastrocnemius & 16.5--29.5 & $21.30 \pm 2.9$ \\
\hline & 2 & Width of tendon at junction with gastrocnemius & $3.42-6.84$ & $4.93 \pm 0.76$ \\
\hline & 3 & Width of tendon at insertion & $2.51-4.5$ & $3.5 \pm 0.54$ \\
\hline & 4 & Width of tendon at $4 \mathrm{~cm}$ & $1.2-2.0$ & $1.49 \pm 0.24$ \\
\hline & 5 & Minimum width of tendon & $1.0-1.82$ & $1.30 \pm 0.16$ \\
\hline & 6 & Distance of minimum width from insertion & $4.0-8.14$ & $5.16 \pm 0.91$ \\
\hline & 7 & Thickness of tendon at insertion & $0.49-1.14$ & $0.82 \pm 0.22$ \\
\hline & 8 & Length of gastrocnemius aponeurosis in the midline & $4-29.5$ & $19.56 \pm 5.88$ \\
\hline & 9 & Length of Gastrocnemius aponeurosis medially & $13.1-28.5$ & $21.86 \pm 3.05$ \\
\hline & 10 & Length of Gastrocnemius aponeurosis laterally & $15.0-32.7$ & $24.10 \pm 2.95$ \\
\hline
\end{tabular}

Table 2: Comparison of the Measurements taken in the present study with measurements available from various studies.

\begin{tabular}{|c|l|c|c|c|c|c|}
\hline \multicolumn{1}{|c|}{ MEASUREMENTS (cm) } & $\begin{array}{c}\text { Present study } \\
\text { (Cadaveric) }\end{array}$ & $\begin{array}{c}\text { Ghany Hassan } \\
\text { Ollo [7] } \\
\text { (Cadaveric) }\end{array}$ & $\begin{array}{l}\text { P. Kharate \& K.C. } \\
\text { Larsen[12] (usg) }\end{array}$ & $\begin{array}{c}\text { Pang \& Yang [8] } \\
\text { (usg) }\end{array}$ & $\begin{array}{c}\text { R A F de Mello [13] } \\
\text { (usg) }\end{array}$ \\
\hline 1 & Length of tendon at junction with gastrocnemius & $21.30 \pm 2.9$ & $22.18 \pm 3.12$ & & $11.77 \pm 2.37$ & \\
\hline 2 & Width of tendon at junction with gastrocnemius & $4.93 \pm 0.76$ & $6.62 \pm 0.52$ & & & \\
\hline 3 & Width of tendon at 4cm & $1.49 \pm 0.24$ & $2.55 \pm 0.34$ & & & \\
\hline 4 & Minimum width of tendon & $1.30 \pm 0.16$ & & & & \\
\hline 5 & Width of tendon at insertion & $3.5 \pm 0.54$ & & & & \\
\hline 6 & Distance of minimum width from insertion & $5.16 \pm 0.91$ & & & & \\
\hline 7 & Thickness of tendon at insertion & $0.82 \pm 0.21$ & & $0.37 \pm 0.06$ & $0.51 \pm 0.06$ & $0.55 \pm 0.06$ \\
\hline 8 & Length of Gastrocnemius aponeurosis medially & $21.86 \pm 3.05$ & & & & \\
\hline 9 & Length of Gastrocnemius aponeurosis laterally & $24.1 \pm 2.95$ & & & & \\
\hline
\end{tabular}

Study of seventy adult cadaveric lower limbs showed presence of Achilles tendon in all the cadaveric limbs. Bursa between tendon at insertion and calcaneus was present in all the specimen.

The mean length of the tendon of gastrocnemius was $21.30 \pm 2.9 \mathrm{~cm}(16.5-29.5 \mathrm{~cm})$ and that of soleus was $7.5 \pm 7.08 \mathrm{~cm}(4.5-10 \mathrm{~cm})$. The width of the Achilles tendon was observed as $4.93 \pm 0.76 \mathrm{~cm}(3.42-6.84 \mathrm{~cm})$ at musculotendinous junction with gastrocnemius and 1.16 $\pm 0.34 \mathrm{~cm}$ at musculotendinous junction with soleus.

At insertion the width of the tendon was $3.5 \pm 0.54 \mathrm{~cm}$. (2.51- $4.5 \mathrm{~cm})$. Minimum width was observed as $1.30 \pm 0.16 \mathrm{~cm}(1.0-1.82 \mathrm{~cm})$ and its average distance from insertion was 5.16 $\pm 0.91 \mathrm{~cm}(4.0-8.14 \mathrm{~cm})$. We also noted the width of the tendon at $4 \mathrm{~cm}$ from the insertion and it was $1.49 \pm 0.24 \mathrm{~cm}$. $(1.2-2 \mathrm{~cm})$. Mean thickness at insertion was $0.82 \pm 0.21 \mathrm{~cm}(0.49$ $-1.14 \mathrm{~cm}$ ).

Length of gastrocnemius aponeurosis was 19.56 $\pm 5.88 \mathrm{~cm}(4-29.5 \mathrm{~cm})$ in the midline, $21.86 \pm$ $3.05 \mathrm{~cm}(13.1-28.5 \mathrm{~cm})$ on its medial side and
$24.10 \pm 2.95 \mathrm{~cm}(15.0-32.7 \mathrm{~cm})$ on the lateral side (Table no.1)

\section{DISCUSSION}

The calcaneal tendon is the thickest and strongest tendon in the human body which is attached to the midpoint of the posterior surface of the calcaneus. The mid substance of the tendon is relative avascular and is a frequently susceptibility to rupture, degenerative changes (tenosinovitis) and inflammation (paratendinitis) [1].

Singh et al[3] reported a case where the lateral and medial heads of gastrocnemius were fleshy in its entire length till its insertion, thus total absence of tendinous portion. In the present study we did not find such variation.

Abdel-Ghany and Ollo[7], in their cadaveric study, observed the mean length of gastrocnemius tendon as $22.18 \pm 3.12 \mathrm{~cm}$, while it was $21.30 \pm 2.9 \mathrm{~cm}$ in the present study. Pang and Ying[8] reported the mean length as $11.77 \pm 2.37$ $\mathrm{cm}$ in their ultrasonographic study of achilles tendon.

Abdel- Ghany and Ollo[7] observed the mean 
width at its junction with gastrocnemius muscle as $6.62 \pm 0.52 \mathrm{~cm}$ while it was less in the present study i.e. $4.93 \pm 0.76 \mathrm{~cm}$. They observed the width as $2.88 \pm 0.32 \mathrm{~cm}$ at its junction with soleus while we observed it as $1.16 \pm 0.34 \mathrm{~cm}$. At insertion the width was $2.55 \pm 0.34 \mathrm{~cm}$ in the study done by Ghany- Hassan and Ollo[7], while in the present study it was $3.5 \pm 0.54 \mathrm{~cm}$. The variation in the differences in population height could account for the differences in tendon thickness[11].

Mean thickness of the Achilles tendon at insertion was observed as $0.82 \pm 0.21 \mathrm{~cm}$. Pang and Ying[8] reported mean thickness as $0.51 \pm$ $0.06 \mathrm{~cm}$. Kharate and Larsen[12] reported it as $0.37 \pm 0.06 \mathrm{~cm}, \mathrm{RAF}$ de Mello[13] reported it as $0.55 \pm 0.06 \mathrm{~cm}$. The difference can be explained as the methods of study were different. All these three studies were done by ultrasonography while we studied the cadavers. (Table no.2) Detailed knowledge of anatomic variation of the Soleus muscle at its insertion point onto the tendoachillis has clinical implications when repairing the tendon following rupture. It also helps in the planning of reconstructive surgery using soleus muscle flap[10]. Length from the musculotendinous junction of soleus to its insertion was $7.62 \pm 1.71 \mathrm{~cm}$ in the study conducted by Ghany-hassan and Ollo[7], while it was observed as $7.5 \pm 7.08 \mathrm{~cm}$ in the present study. Balius et al.[9] in their MRI study of soleus observed it as $6.42 \pm 2.18 \mathrm{~cm}$ (range $3.3-$ 11.8)and Pitchler et al.[10] noted the range from 2.54 to $7.62 \mathrm{~cm}$.

In some cases the gastrocnemius muscle inserts superficially, onto the tendon of the soleus; though in most cases, the distal end of gastrocnemius aponeurosis extends for a variable distance as a thin, tendinous sheet void of muscular attachments. Surgeons performing a gastrocnemius recession may target the exposed inferior portion of the aponeurosis that is not directly covered by muscle[14]. Barford and Pers[15] first described use of the lateral belly of the gastrocnemius muscle, after detaching it from its lower insertion to cover the eroded condyles and the gaping knee while the medial gastrocnemius muscle flap plasty was first described by Ger[16].

In the present study we found that the mean length of the medial border of the gastrocnemius aponeurosis was $21.86 \pm 3.05 \mathrm{~cm}$ and on the lateral side it was $24.10 \pm 2.95 \mathrm{~cm}$. In pathological conditions of the foot and ankle, Gastrocnemius muscle plays a vital role. Conditions such as gastrocnemius equinus are treated by the Endoscopic gastrocnemius recession (EGR)[17]. The morphology of the conjoint junction of the tendons of gastrocnemius and soleus and the location of the gastrocnemius tendon relative to bony landmarks would help in incision planning for open or endoscopic division of tendon[18]. A detailed understanding of the variations in the gastrocnemius aponeurosis as well as of the morphological aspects of triceps surae will help the surgeon to choose the appropriate recession technique. It will also help in accurately performing the procedure and avoiding complications like sural nerve injuries [17].

Due to the increasing number of implantation of knee endoprostheses and the associated number of soft tissue damages, a standardized procedure for the treatment of these complications is necessary. In the case of deep soft tissue damages with fistulae reaching the prosthesis or exposing the prosthesis, the gastrocnemius muscle flap is a good method for secure coverage of the prosthesis with wellperfused tissue[19]. Detail anatomical and morphological knowledge of gastrocnemius can be useful to surgeons in planning of the surgery.

\section{CONCLUSION}

Understanding the variations in morphology of the achilles tendon and aponeurosis of gastrocnemius muscle, will be useful to the Anatomists as it will help them integrate the variations in their routine teaching and thus help them to prepare the students better for their clinical tenures.

This knowledge will aid the surgeon in choosing the recession technique, planning the incision, performing surgical procedures such as repair of a ruptured tendon, pedicle muscle flap for reconstructive surgery and arthroplasty, Endoscopic Gastrocnemius Recession surgery. It will prevent iatrogenic complications like nerve injuries. 


\section{ACKNOWLEDGEMENTS}

The authors would like to acknowledge the help given by Dr. J. Garcha in data collection.

\section{Conflicts of Interests: None}

\section{REFERENCES}

[1]. Standring S, Gray'sAnatomy- The anatomical basis of clinical practice $40^{\text {th }}$ edition. London UK: Elsevier; 2008:884-886.

[2]. Nigel Palastanga, Derek Field, Roger Soames, Butterworth Henemann .Anatomy and human movement; structure and function. Fifth edition. 2006; Elsevier Ltd.:292.

[3]. Gurubachan Singh, Vijay Prakash Agrawal, M Basavarajappa, M Manohar. Gastrocnemius Achilles tendon: A human anatomical variation. IJBAR 2012; 03(08): 653-655.

[4]. Lichtwark GA, Wilson AM. In vivo mechanical properties of the human Achilles tendon during onelegged hopping. J ExpBiol 2005;208 (24):4715-25.

[5]. Sella EJ. Disorders of the Achilles tendon and its insertion. Clin Pediatr Med Surg 2005;22(1):87-99

[6]. Georges Y, El-Khoury. Essentials of musculoskeletal imaging, Churchill livingstone 2003:586-87.

[7]. Abdel-Ghany AGH, Ollo HA; Anatomical and histological study of the tendoachilles. Bull Alex Fac Med. 2008; 44(3). Available from www.med.alexu.edu.eg/ journal/index. php/bulletin/article/down load/.../ 242

[8]. Pang BSF, Ying M. Sonographic measurement of Achillis tendon in asymptomatic subjects. J Ultrasoundin medicine 2006; 25: 1291-1296.

[9]. Balius R, Alomar X, Rodas G, Miguel-Pérez M, Pedret C, Dobado MC, Blasi J, Koulouri G. The soleus muscle: MRI, anatomic and histologic findings in cadavers with clinical correlation of strain injury distribution. Skeletal Radiol 2013; 42: 521-530.

[10]. Pichler W, Tesch NP, Grechenig W, Leithgoeb O, WindischG. Anatomic variations of the musculotendinous junction of the soleus muscle and its clinical implications. ClinAnat 2007;20(4):444-7.

[11]. Koivunen-Niemelä, T. Parkkola, K. Anatomy of the Achilles tendon (tendo calcaneus) with respect to tendon thickness measurements. SurgRadiolAnat .1995; 17: 263.
[12]. Kharte and Larsen.Ultrasound evaluation of Achilles tendon thickness in asymptomatic'-s: A reliability study. International journal of physiotherapy and rehabilitation. nov 2012; 2:1-11.

[13]. De mello RAF, Marchiori E, Alair Augusto S.M.D. dos Santos, Neto GT. Morphometric evaluation of Achilles tendon by ultrasound. Radiol Bras 2006; 39(3).

[14]. Neal M Blitz, David j. Eliot. Anatomical aspect of the Gastrocnemius aponeurosis and its insertion: A cadaveric study. Journal of Foot \& Ankle surgery 2007; 46(2):101-108.

[15]. Barfod Band Pers M. Gastrocnemius-plasty for primary closure of Compound injuries of the knee. The journal of bone and joint surgery1970; $52 \mathrm{~b}(\mathrm{I})$.

[16]. Ger R. The technique of muscle transposition in the operative treatment of traumatic and ulcerative lesion of leg. J Trauma1971;11(6):502-11.

[17]. Nitya J and Mariya. Morphological aspects of Triceps surae - A Cadaveric Study. International journal of innovative research \& development 2013; 2 (7): 372-76.

[18]. Elson DW, Whiten S, Hillman SJ, Johnson RJ, Lo SS, Robb JE. The conjoint junction of the triceps surae: implications for gastrocnemius tendon lengthening. Clin Anat. 2007; 20(8):924-8.

[19]. Mobius B, Scheller EE. The pediculated gastrocnemius muscle flap as a treatment for soft tissue problems of the knee - indication, placement and result. GMS Interdiscip Plast Reconstr Surg DGPW 2012; 1.

[20]. Browner, Jupiter, Levine, Trafton. Skeletal trauma: Basic science, management and Reconstruction. VolII. Saunders Publication 2003:1893

[21]. Holinshead WH; The Back and Limbs, In Anatomy for surgeons. $3^{\text {rd }}$ edition, volume 3, New York; Harper and Row publishers,1982:773-778.

[22]. Maffuli N, Sharma P, Luscombe K L; Achilles tendinopathy: aetiology and management. Journal of Royal Society of Medicine 2004;97:472-476.

How to cite this article:

Pallavi Bajpayee, Shilpa Gosavi, P Vatsalaswamy. MORPHOLOGICAL STUDY OF ACHILLES TENDON. Int J Anat Res 2019;7(1.2):6234-6238. DOI: $10.16965 /$ ijar.2018.448 